\title{
Performance of All-Metal Demountable Cryogenic Seals at Superfluid Helium Temperatures
}

Louis J. Salerno, Ames Research Center, Moffett Field, California Alan L. Spivak, Trans-Bay Electronics, Richmond, California

Peter Kittel, Ames Research Center, Moffett Field, California

\section{N/SN}

National Aeronautics and

Space Administration

Ames Research Center

Moffett Field, California 94035 


\title{
PERFORMANCE OF ALL-METAL DEMOUNTABLE CRYOGENIC SEALS AT SUPERFLUID HELIUM TEMPERATURES *
}

\author{
Louis J. Salemo ${ }^{\dagger}$ \\ NASA Ames Research Center \\ Moffett Field, CA 94035 \\ Alan L. Spivak $\ddagger$ \\ Trans-Bay Electronics \\ Richmond; CA 94804 \\ and \\ Peter Kittel ${ }^{\dagger}$ \\ NASA Ames Research Center \\ Moffett Field, CA 94035
}

\section{Abstract}

Two all-metal demountable cryogenic seals with an outside diameter of $36.6 \mathrm{~mm}$, inside diameter of $27.2 \mathrm{~mm}$, and thickness of $0.51 \mathrm{~mm}$ were leak-tested at room temperature $(300 \mathrm{~K})$, liquid nitrogen temperature ( 21 cycles at $77 \mathrm{~K}$ ), liquid helium temperature ( 9 cycles at $4.2 \mathrm{~K}$ ), and superfluid helium temperature ( 4 cycles at $1.6 \mathrm{~K}$ ). Each seal was mounted and demounted for 13 cycles. Thickness measurements at $90^{\circ}$ intervals along the circumference showed a maximum seal compression of $0.038 \mathrm{~mm}$. Leak-rate measurements at all temperatures showed no detectable leak above the helium background level, typically $0.1 \times 10^{-9} \mathrm{std}-\mathrm{cc} / \mathrm{sec}$, during testing.

\section{Intorduction}

In the past, Wood's metal, copper, aluminum, tin, and indium have been used to make demountable seals for cryogenic applications. Indium in particular has been used with excellent results because of the ease of fabricating an O-ring from indium wire. One of the problems of using indium is that leakage frequently occurs under rapid cooling as a result

\footnotetext{
*The identification in this paper of certain commercial products does not imply recommendation or endorsement by the National Aeronautics and Space Administration, nor does it imply that the products identified are necessarily the best available for the purpose.

tResearch Scientist.

‡Research Technician.
}

Copyright $\odot 1989$ by the American Institute of Aeronautics and Astronautics, Inc. No copyright is asserted in the United States under Title 17, U.S. Code. The U.S. Government has a royalty-free license to exercise all rights under the copyright claimed herein for Governmental purposes. All other rights are reserved by the copyright owner. of the differential contraction between the seal and the mating materials. ${ }^{1}$

Such commercial products as Varian Conflat ${ }^{\mathrm{TM}}$ flanges have been used to address the sealing problem by providing a disposable copper ring which seals against stainless steel knife edges. These seals provide excellent results. The only disadvantage is that a new gasket must be used each time the flange is disassembled and reassembled. A need exists for a demountable cryogenic seal which is leak-tight at superfluid helium ( $\mathrm{SfHe}$ ) temperatures after repeated cycling.

Creare, Inc., developed a reusable static cryogenic seal for applications such as cryogenic turbo-expander inlet and exhaust lines, and cryogenic sensor mounts. 2

The annular-shaped seal consists of a flat indium/silver -alloy seal surrounded at both the inside and outside diameters by a 316 stainless steel guard. The seal has an outside diameter of $36.6 \mathrm{~mm}$, an inside diameter of $27.2 \mathrm{~mm}$, and a thickness of $0.51 \mathrm{~mm}$ (see Fig. 1).

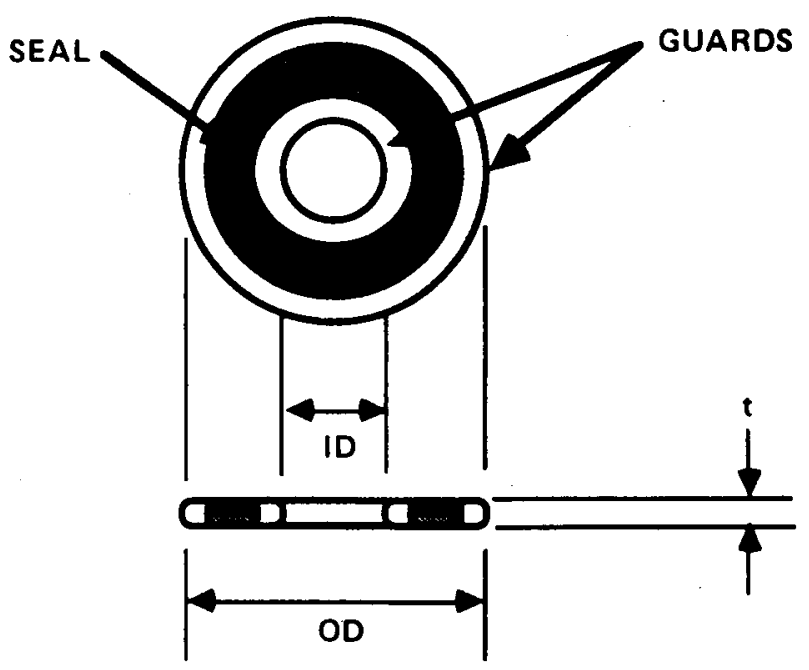

Fig. 1 Diagram of seal. 
The manufacturer recommends face mounting between bolted flanges with a maximum of five complete mounting/ demounting cycles. Flange bolts are to be torqued in at least three steps to generate a compressive force of $11,000 \mathrm{lbf}$ $(49,000 \mathrm{~N}) \pm 110 \mathrm{lbf}(490 \mathrm{~N})$ on the seal.

\section{Method}

Figures 2 and 3 show the flange assembly designed for testing the seals. The smooth surfaces of two Varian
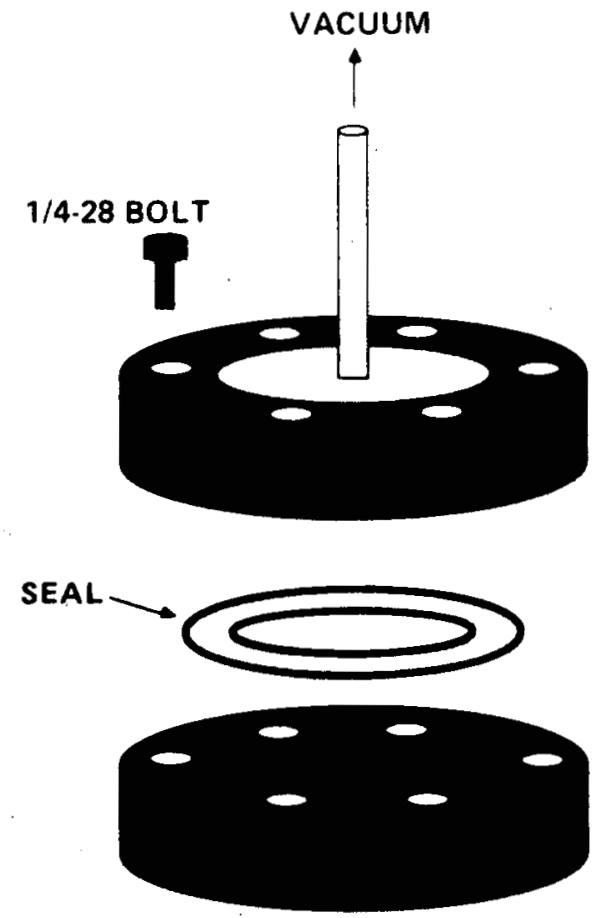

Fig. 2 Conflat ${ }^{\mathrm{TM}}$ flange assembly.
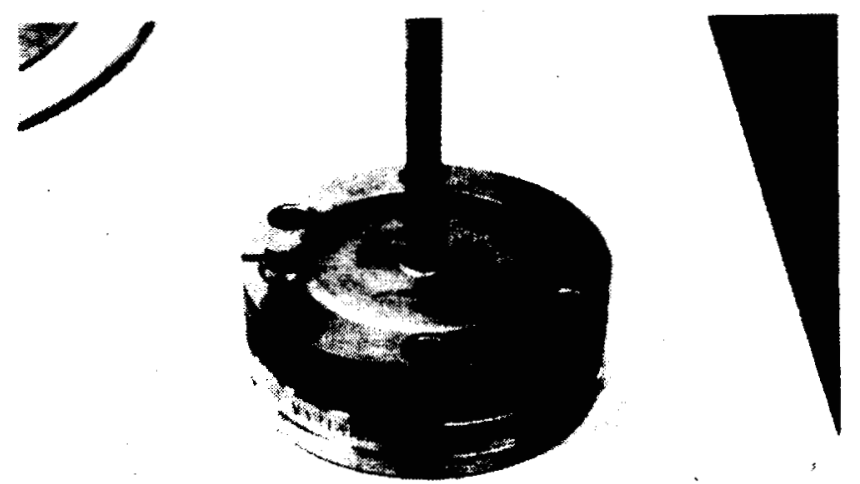

Fig. 3 Flange assembly.
Conflat ${ }^{\mathrm{TM}}$ flanges were used as the sealing surfaces. A port drilled in the upper flange accommodated a 0.25 -in.

(6.3- $\mathrm{mm}$ ) evacuation tube which was silver soldered to the flange. Figure 4 shows one of the seals resting on the lower flange. The upper flange is to the right and the evacuation port is visible in the center of the flange.

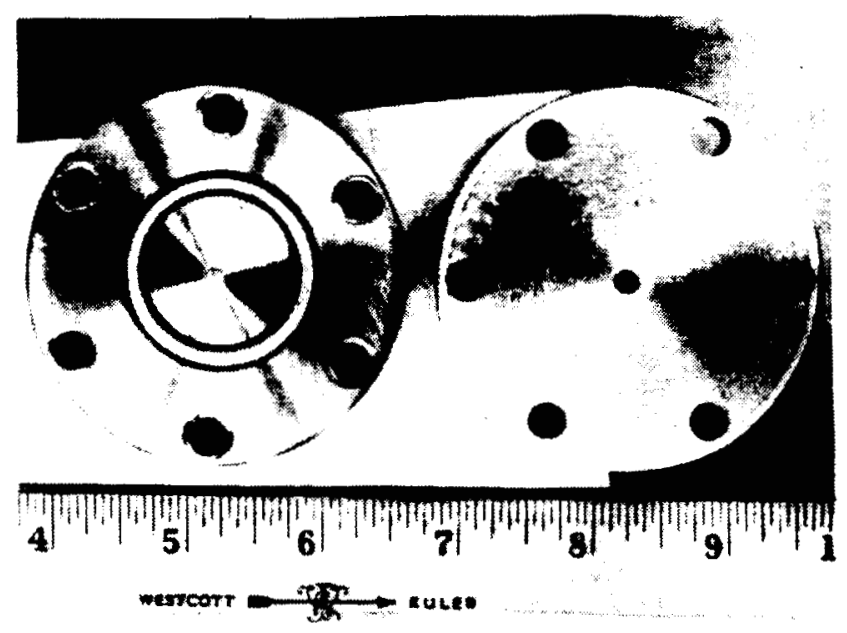

Fig. 4 Seal resting on flange.

The flanges were bolted together with six 1/4-28 bolts and nuts. The tightening torque required to generate a compressive force of $11,000 \mathrm{lbf}(49,000 \mathrm{~N})$ at the seal was calculated to be $91.5 \mathrm{in}-1 \mathrm{~b}(10.4 \mathrm{~N}-\mathrm{m})$ per bolt.

The flange assembly was mounted into a cryostat and installed in a Dewar. By evacuating the Dewar, SfHe temperatures were achieved. Figure 5 shows the experimental setup. Table 1 presents the details of the test procedure.

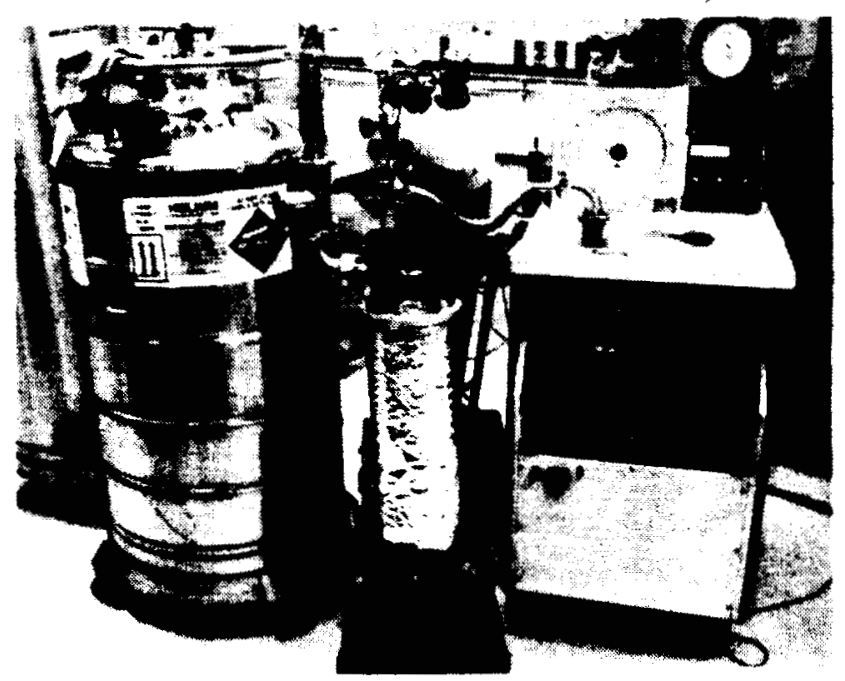

Fig. 5 Experimental setup. 
Table 1 Cryogenic seal test procedure

\begin{tabular}{|c|c|c|c|c|}
\hline & Nom & al leak c & $k$ tempe & ure \\
\hline Task & $300 \mathrm{~K}$ & $77 \mathrm{~K}$ & $4.2 \mathrm{~K}$ & $1.6 \mathrm{~K}$ \\
\hline $\begin{array}{l}\text { Assembly } \\
\mathrm{LN}_{2} \text { leak test } \\
\text { Room-temperature leak test } \\
\text { LHe leak test (5 cycles) } \\
\text { Room-temperature leak test } \\
\text { Cryostat mounting } \\
\text { SfHe leak test } \\
\text { Room-temperature leak test } \\
\text { Disassembly } \\
\text { Seal inspection/measurement } \\
\text { Reassembly } \\
\text { LN2 leak test } \\
\text { Room-temperature leak test } \\
\text { Cryostat mounting } \\
\text { SfHe leak-test procedure } \\
\text { Room-temperature leak test } \\
\text { Disassembly } \\
\text { Seal inspection/measurement } \\
\text { Reassembly } \\
\text { LN2 leak test (7 cycles) } \\
\text { Room-temperature leak test } \\
\text { Disassembly } \\
\text { Seal inspection/measurement } \\
\text { Reassembly } \\
\text { Cryostat mounting } \\
\text { SfHe leak test } \\
\text { Room-temperature leak test } \\
\text { Disassembly } \\
\text { Seal inspection/measurement } \\
\text { Reassembly } \\
\text { LN2 leak test (6 cycles) } \\
\text { Room-temperature leak test } \\
\text { Disassembly } \\
\text { Seal inspection/measurement } \\
\text { Reassembly } \\
\text { Cryostat mounting } \\
\text { SfHe leak test } \\
\text { Room-temperature leak test }\end{array}$ & $\begin{array}{l}\mathbf{x} \\
\mathbf{x} \\
\mathbf{x} \\
\mathbf{x} \\
\mathbf{x} \\
\mathbf{x} \\
\mathbf{x} \\
\mathbf{x}\end{array}$ & $x$ & $x$ & $x$ \\
\hline
\end{tabular}

Prior to testing, the seal was inspected for pits, irregularities, and radial scratches on the stainless steel guards, which could affect the sealing properties. Grooves were noted on the seals in the circumferential direction. Small nicks and scratches, which proved to be inconsequential, were present on the indium/silver surface. Measurements of the seal thickness were taken at $90^{\circ}$ locations around the circumference of the seal.

The seal was centered between the flanges, and the bolts were installed. A tightening sequence was used to assure a uniform preload of the seal. The sequence pattern was repeated in four steps beginning with a torque of $25 \mathrm{in}-1 \mathrm{~b}$ 
$(2.84 \mathrm{~N}-\mathrm{m})$ and with increases of approximately 25 in-lb per step. This procedure was followed wherever reassembly was appropriate.

\section{Results}

During the tests, each seal underwent 21 temperature cycles at liquid nitrogen $\left(\mathrm{LN}_{2}\right)$ temperature, 9 cycles at liquid helium ( $\mathrm{LHe}$ ) temperature, and 4 cycles at SfHe temperature. In addition, each seal was mounted and demounted 13 times.

For the first seal tested, the measured leak rate was below the background at all times during the tests. Background was typically $0.1 \times 10^{-9}$ std-cc/sec, reaching a maximum of $0.4 \times 10^{-9} \mathrm{std}-\mathrm{cc} / \mathrm{sec}$ within a short time after filling the Dewar with LHe, because of the large amount of helium gas in the laboratory.

Results of the thickness measurements showed that, starting with a measured thickness of $0.0200 \mathrm{in} .(0.51 \mathrm{~mm})$, minimum thickness after 15 assembly/disassembly cycles was 0.0185 in. $(0.470 \mathrm{~mm})$ at one of the $90^{\circ}$ quadrants. The other three values were $0.0200,0.0195$, and 0.0190 in

For the second seal tested, the procedure of filling the Dewar was altered to allow for filling it outside the laboratory. This kept the residual background at a maximum of $0.1 \times 10^{-9} \mathrm{std}-\mathrm{cc} / \mathrm{sec}$ during helium and SfHe testing. As with the first seal tested, the measured leak rate was below the background at all times during the tests.

Results of the thickness measurements showed that, starting with a measured thickness of 0.0200 in. $(0.51 \mathrm{~mm})$, minimum thickness after 15 assembly/disassembly cycles was $0.0190 \mathrm{in}$. at all four quadrants. Prior to testing, the seal was marked on both sides of the stainless steel guard, and at each assembly/disassembly the seal was replaced with the two sides exchanged from the previous position.

\section{Discussion}

The results indicate that for both seals tested no measurable leak occurred either at $\mathrm{LN}_{2}$, LHe, or SfHe temperatures, even after the flange assembly was valved off from the leak detector at one point for 10 minutes at SfHe temperature to determine any accumulation effects.
Cooldown and warmup were rapid. Cooldown was accomplished by immersing the flange assembly in cryogen and warmup was accomplished by immersing the flange in hot water. Ice formation, as a result of transferring the flange assembly from cryogen to hot water, did not appear to affect the seals.

After the test was completed, some dirt was present on the indium/silver sealing surface in a few places around the seals' circumference. This did not appear to affect the sealing properties, and the dirt was easily removed with a cloth moistened in ethanol.

Aside from the slight compression of the seal noted in the results, no degradation of seal performance resulting from temperature cycling and/or mounting/demounting were noted, even though the number of mounting/demounting cycles exceeded the manufacturer's recommendation by a factor of 2.6 .

\section{Y. Conclusion}

The experimental results of testing two all-metal, demountable, cryogenic seals showed that after 13 complete mounting and demounting cycles and 21 cryogenic temperature cycles, 9 of which were at $4.2 \mathrm{~K}$ and 4 of which were at $1.6 \mathrm{~K}$, the measured leak rate of the seals was below the residual background of the leak detector. This background was typically $0.1 \times 10^{-9}$ std-cc/sec and reached a maximum of $0.4 \times 10^{-9} \mathrm{std}-\mathrm{cc} / \mathrm{sec}$ because of the large quantities of helium transfer gas present in the laboratory.

These results exceed the manufacturer's data by an order of magnitude for the leak rate and a factor of 2.6 for the mounting/demounting recommendation.

\section{References}

'White, G. K., "Experimental Techniques in LowTemperature Physics," Clarendon Press, Oxford, 1979.

2U-Guard Seal, Creare, Inc., Etna Road, P.O. Box 71, Hanover, NH 03755. 


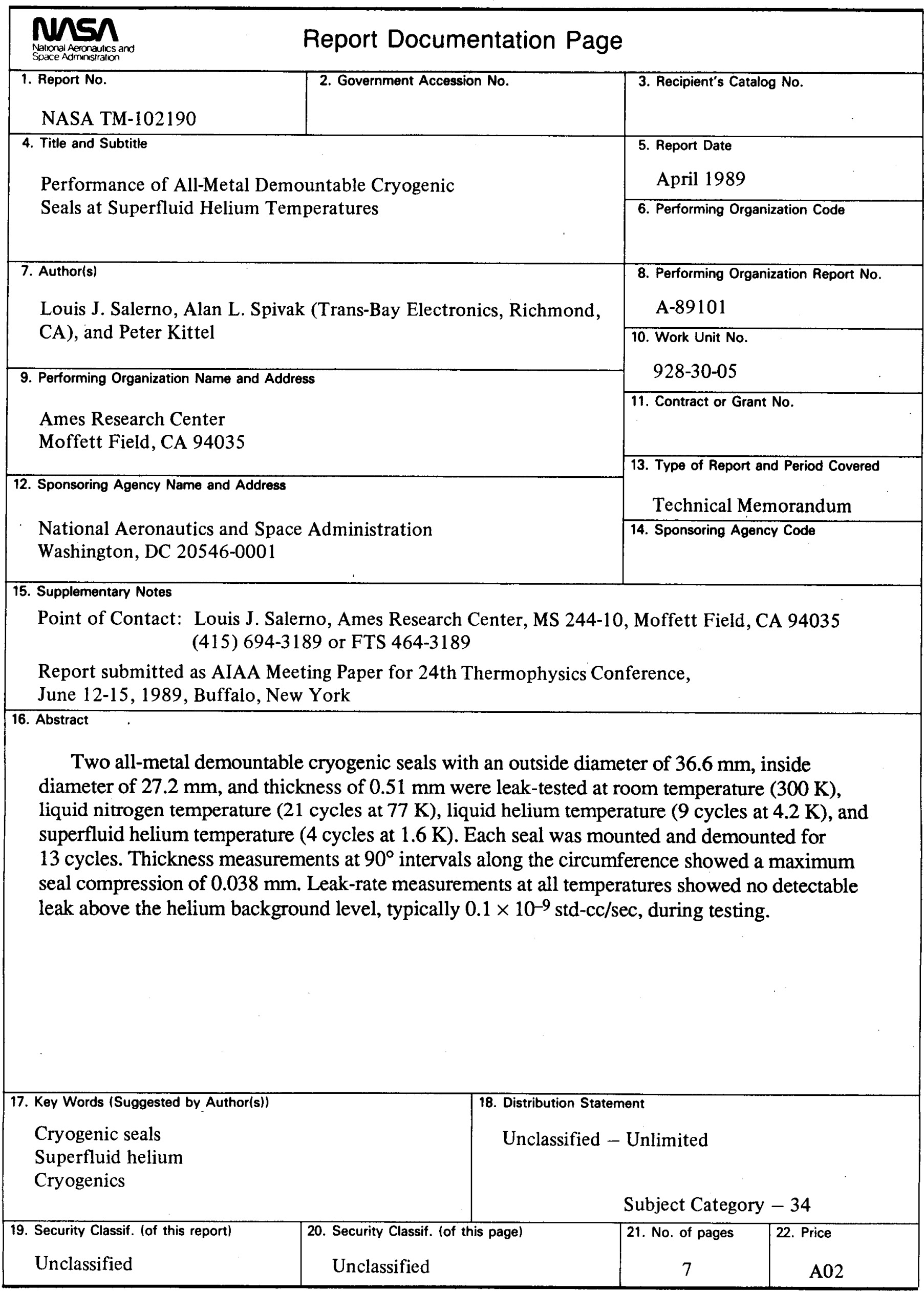

